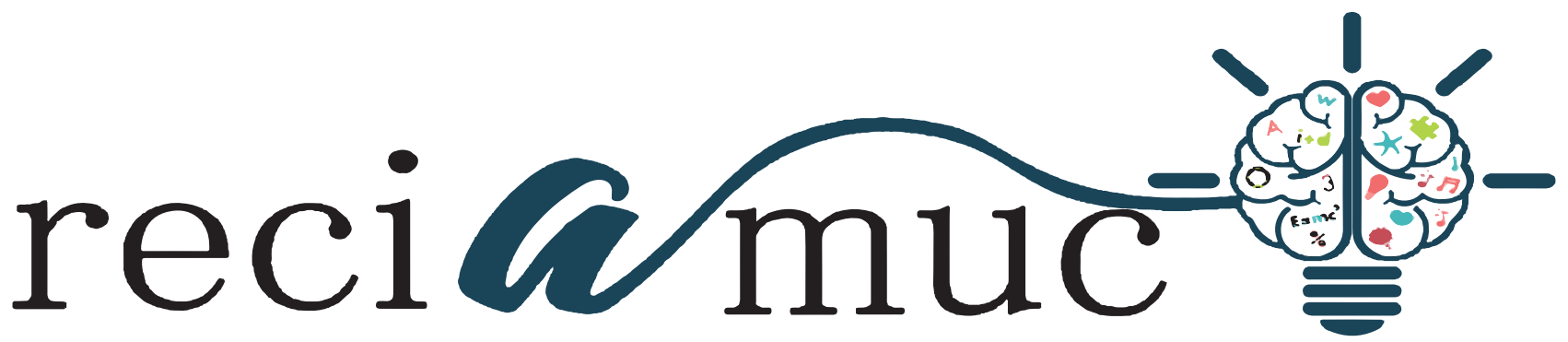

DOI: 10.26820/reciamuc/4.(3).julio.2020.298-309

URL: https://reciamuc.com/index.php/RECIAMUC/article/view/530

EDITORIAL: Saberes del Conocimiento

REVISTA: RECIAMUC

ISSN: 2588-0748

TIPO DE INVESTIGACIÓN: Artículo de Revisión

CÓDIGO UNESCO: 3202 Epidemiología; 3205 Medicina Interna

PAGINAS: 298-309

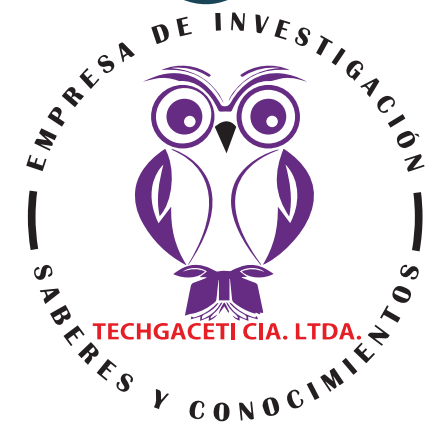

\title{
Factores de riesgo en los recién nacidos infectados por COVID-19
}

Risk factors in newborns infected by COVID-19

Fatores de risco em recém-nascidos infectados pelo COVID-19

\author{
Andrea Elizabeth Alcivar Cedeño'; Cinthya Elizabeth Alava Alvarado2; \\ Maria Elena Pincay Cañarte3; Tania Mercedes Alcázar Pichucho ${ }^{4}$ \\ RECIBIDO: 20/05/2020 ACEPTADO: 19/07/2020 PUBLICADO: 30/07/2020
}

1. Médico Cirujano; Médico Residente del área de Neonatologia del Hospital Rodríguez Zambrano; Manta, Ecuador; andreayjeanluca@gmail.com; (iD https://orcid.org/0000-0003-3817-9846

2. Médico Cirujano; Médico de Emergencia del Centro de Salud Cuba Libre; Manta, Ecuador; cinthya-alava14@hotmail.com; (iD) https://orcid.org/0000-0001-8662-302X

3. Licenciada en Enfermería; Magíster en Gerencia en Salud para el Desarrollo Local; Docente Titular de la Carrera de Enfermería - Unesum; Jipijapa, Ecuador; maria.pincay@hotmail.com - maria.pincay@unesum.edu.ec; iD https://orcid.org/00000003-4110-9275

4. Licenciada en Enfermería; Magíster en Gerencia en Salud para el Desarrollo Local; Docente Titular de la Carrera de Enfermería - Unesum; Jipijapa, Ecuador; mercedes.alcazar@unesum.edu.ec; (iD https://orcid.org/0000-0001-7440-5447

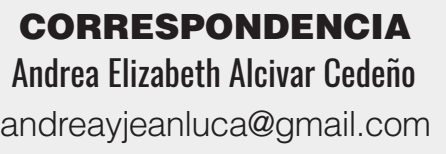

Manta, Ecuador 


\section{RESUMEN}

La infección con el virus SARS- CoV-2 en los recién nacidos (RN) fundamentalmente ocurre, como en todos los casos, por medio de gotas de saliva que el bebé inhala o ingresa por la boca, razón por la que esta transmisión puede darse durante el período postnatal. Puede causar afecciones clínicas que van desde la eliminación viral asintomática, a una enfermedad leve similar al resfriado común o hasta, inclusive, una enfermedad grave con neumonía multifocal. Lo que ha estimulado el desarrollo de la presente investigación ha sido la persistente necesidad de todos los profesionales de la salud de mantenerse informado en los contenidos que les competen. En razón de ello, se ha expuesto sobre los factores de riesgos en los RN infectados por COVID 19, partiendo de una investigación bibliográfica y una metodología de revisión. En los resultados se logra hacer una exposición basada, fundamentalmente, en el criterio de varios entendidos que han sido extraídos de las fuentes consultadas. Se concluye que: no existe aún evidencia definitiva que sustente una clara relación entre tales morbilidades y el riesgo que representa para un RN con la COVID 19.

Palabras clave: Neonatos, prematuridad, trombocitopenia, transmisión, comorbilidad.

\section{ABSTRACT}

Infection with the SARS-CoV-2 virus in newborns (NBs) fundamentally occurs, as in all cases, through drops of saliva that the baby inhales or enters through the mouth, which is why this transmission can occur during the postnatal period. It can cause clinical conditions ranging from asymptomatic viral shedding, to a mild illness similar to the common cold, or even severe illness with multifocal pneumonia. What has stimulated the development of this research has been the persistent need for all health professionals to stay informed on the content that concerns them. For this reason, it has been exposed about the risk factors in newborns infected by COVID 19, based on a bibliographic research and a review methodology. In the results it is possible to make a presentation based, fundamentally, on the criteria of various experts that have been extracted from the sources consulted. It is concluded that: there is still no definitive evidence that supports a clear relationship between such morbidities and the risk it represents for an NB with COVID 19.

Keywords: Neonates, prematurity, thrombocytopenia, transmission, comorbidity.

\section{RESUMO}

A infecção pelo vírus SARS-CoV-2 em recém-nascidos (RN) ocorre fundamentalmente, como em todos os casos, por meio de gotas de saliva que o bebê inala ou entra pela boca, razão pela qual essa transmissão pode ocorrer no período pós-natal. Pode causar condições clínicas que variam de disseminação viral assintomática a uma doença leve semeIhante ao resfriado comum ou até mesmo doença grave com pneumonia multifocal. O que tem estimulado o desenvolvimento desta pesquisa foi a necessidade persistente de todos os profissionais de saúde se manterem informados sobre o conteúdo que lhes diz respeito. Por esse motivo, expôs-se sobre os fatores de risco em recém-nascidos infectados pelo COVID 19, com base em pesquisa bibliográfica e metodologia de revisão. Nos resultados é possível fazer uma apresentação baseada, fundamentalmente, nos critérios de vários especialistas extraídos das fontes consultadas. Conclui-se que: ainda não existem evidências definitivas que sustentem uma relação clara entre tais morbidades e o risco que representam para um RN com COVID 19.

Palavras-chave: Neonatos, prematuridade, trombocitopenia, transmissão, comorbidade. 


\section{Introducción}

En la región de las Américas habitan más de mil millones de personas, donde ocurren al menos 15 millones de nacimientos.

Hasta ahora, en los casos estudiados no hay evidencia sobre la transmisión de madre a hijo en mujeres con infección durante el tercer trimestre de gestación, basándose en estudios que han reportado muestras negativas de líquido amniótico, sangre de cordón, secreción vaginal, hisopados de garganta neonatal o leche materna.

Del mismo modo, no es consistente la evidencia acerca de resultados graves en mujeres gestantes o en recién nacidos y se limita a mujeres cuya infección fue confirmada en el tercer trimestre, con algunos casos de ruptura prematura de membranas, sufrimiento fetal y parto prematuro notificados. (OMS, 2020, págs. 1-2)

"...las mujeres embarazadas con COVID-19 podrían tener mayor riesgo de registrar resultados adversos durante el embarazo, como el nacimiento prematuro." (Centros para el Control y Prevención de Enfermedades de los Estados Unidos de América, 2020)

Según Berberian (2020) la infección con el virus SARS- CoV-2 en los recién nacidos ( $R N$ ) fundamentalmente ocurre, como en todos los casos, por medio de gotas de saliva que el bebé inhala o ingresa por la boca, razón por la que esta transmisión puede darse durante el período postnatal.

La infección con el SARS-CoV-2 se confirma en los RN con la presencia de uno de los siguientes criterios: Aislamiento del SARS-CoV-2 en muestras de secreciones respiratorias o sangre por Reacción de Polimerasa en Cadena en tiempo real (RT-PCR); o, Determinación del SARS-CoV-2 por secuenciamento viral en muestras de secreciones respiratorias. (Ministerio de Salud Pública y Bienestar Social del Paraguay, 2020)

La infección por SARS-CoV-2 puede causar afecciones clínicas que van desde la eliminación viral asintomática, a una enfermedad leve similar al resfriado común o hasta, inclusive, una enfermedad grave con neumonía multifocal.

A la fecha, la infección COVID-19 no parece tener un impacto particularmente negativo sobre las mujeres embarazadas, como sucediera con las infecciones causadas por coronavirus del síndrome respiratorio agudo grave (SARS-CoV-1) y del síndrome respiratorio de Oriente Medio (MERSCoV) o influenza H1N1.

[...] Los signos y síntomas, especialmente en los RN prematuros, no son específicos. Por lo tanto, es necesario controlar de cerca los signos, los síntomas respiratorios y gastrointestinales, así como la temperatura, que puede estar elevada, baja o normal.

Los pocos casos comunicados sugie- 
ren que puede presentarse con síntomas respiratorios y cardiovasculares, pero puede incluir además mala alimentación, letargo, vómitos, diarrea y distensión abdominal. (Ministerio de Salud de Argentina, 2020)

Sola et al. (2020) aseguran que "Lo que no sabemos es mucho en COVID-19 en el RN y la mujer embarazada, o sea es una evidencia en construcción." (pág. 10)

Según la reciente publicación de la Asociación Colombiana de Neonatología (ASCON):

Los recién nacidos constituyen una población vulnerable, con riesgo aumentado de enfermedad grave, lo cual es contrario a lo descrito en las primeras publicaciones, debido principalmente a su inmunidad inmadura tanto la innata como la adaptativa, a una menor exposición a infecciones y a una menor respuesta al interferón I. (ASCON, 2020)

Lo que ha estimulado el desarrollo de la presente investigación ha sido la persistente necesidad de todos los profesionales de la salud de mantenerse informado en los contenidos que les competen. En razón de ello, con fuentes recientes se procura exponer sobre los factores de riesgos en los RN infectados por COVID 19, partiendo de una investigación de diseño bibliográfico y una metodología de revisión. Con los resultados se hará una aproximación al tema en general, basando el aporte fundamentalmente en los criterios de expertos extraídos de las fuentes consultadas.
La conclusión que al final se presenta, constituye la opinión consensuada a la que llegó el equipo investigador en base a la revisión efectuada.

\section{Materiales y Métodos}

La observación y selección la bibliografía fue adelantada por cada integrante del equipo investigador en la última semana de agosto del corriente, mediante una búsqueda progresiva en: bases de datos (BVS, y PubMed); buscadores especializados (SciELO, Medigraphic, Redalyc, Base, Dialnet) y sitios web específicos (OMS, y alunas revistas científicas).

Fundamentalmente, este proceso estuvo caracterizado por el empleo palabras clave y operadores lógicos que, a manera de ecuaciones de búsqueda, se fueron configurando, por ejemplo, en BVS se usó: "Factores de riesgo" $O$ "riesgos" $Y$ recién nacidos $O$ neonatos $Y$ infectados COVID19; mientras que en PubMed y demás plataformas disponibles en idioma inglés, se utilizó una configuración de palabras equivalentes (con igual o menos palabras claves), quedando la siguiente fórmula: newborns OR neonates AND infected COVID 19 AND Risk factors.

Así, la selección de los contenidos bibliográficos se fue haciendo primordialmente en base a la mayor correlación o coincidencia que, a criterio del equipo investigador, se comprobara entre los títulos de éstos, la ecuación o sintaxis de búsqueda utilizada y el objeto del tema en cuestión, no sin antes haber aplicado otros factores

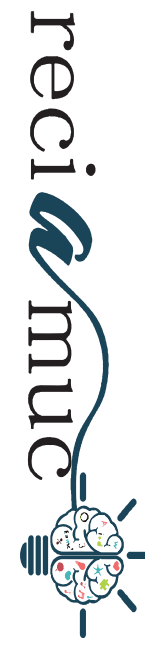


de refinamiento de búsqueda, según se hallasen disponibles en cada una de las citadas plataformas de exploración. En términos generales, estos filtros correspondieron a: disponibilidad del contenido (completo); tipo de acceso al contenido (abierto o cerrado); periodo de publicación (20192020), idioma (español e inglés); tipo de material bibliográfico (libros digitalizados, e-books, protocolos, consensos, manuales, boletines informativos, ensayos clínicos, tesis de grado, posgrado o doctorado, informes, planes y proyectos, y otras clases de contenidos); además incluyendo guías de práctica clínica, estudios de cohorte y revisiones sistemáticas; que preferiblemente estuviesen producidos, avalados o promovidos por instituciones, entes, organizaciones, sociedades o asociaciones de profesionales en el área de la salud, que fueran de carácter público o privado, nacionales, internacionales o multilaterales. Al final de este proceso, fue posible detectar amplias dificultades en cuanto a la escogencia del contenido, ya que en los resultados se encontraron pocas coincidencias en relación a la especificidad del objeto estudio, sin embrago, se estimó recuperar no menos de 10 fuentes para la sustentación de la presente exposición.

Todo el contenido desestimado básicamente consistió en: el material exactamente igual, es decir, repetidos, por haberse encontrado y seleccionado una primera vez ante el uso de cualquier otro canal de búsqueda; cartas editoriales o editoriales, anotaciones académicas y otros tipos de contenidos bibliográficos con escasas de fuentes de sustentación científica o con bajo nivel de evidencia.

Se considera importante aclarar que, en definitiva, tanto la metodología como el análisis y la argumentación aquí evidenciada, en todo momento fue lograda bajo el consenso del equipo investigador.

\section{Resultados}

Mediante la actualización de las orientaciones provisionales de Academia Estadounidense de Pediatría (AAP, por sus siglas en inglés) publicadas el 10 de septiembre del corriente, se expuso que, hasta el momento, los datos recogidos sugieren que cerca del $2 \%$ de los RN de mujeres que han sido diagnosticadas con COVID 19 poco antes del parto, son los que han resultado igualmente positivo en las primeras 24-96 horas después del nacimiento para la misma enfermedad. Aún se desconoce si algún RN, de los reportados ante el Registro de esa misma institución, ha sufrido el contagio en el hogar o luego de haber sido dado de alta en el hospital.

Adicionalmente, ésta asociación destacó que, actualmente, son escazas las publicaciones de series de casos de COVID-19 pediátricos, sin embargo, hacen el llamado a que los especialistas y familiares consideren cautelosamente otros trabajos de investigación publicados en los que se ha reportado la necesidad de hospitalización para RN debido a la infec- 
ción grave por COVID-19.

Después de meses de experiencia nacional e internacional con recién nacidos de madres que han dado positivo para SARS-CoV-2, ningún informe publicado ha identificado a un bebé que ha muerto durante la hospitalización inicial del nacimiento como resultado directo de la infección por SARS-CoV-2. Entre los más de 3.000 parejas maternos-infantiles del Registro Nacional Perinatal COVID-19, la probabilidad de que un bebé tenga una prueba positiva de PCR para SARS-CoV-2 es similar para los lactantes separados de sus madres y para los bebés que se alojan con las madres que utilizan medidas de prevención de infecciones. Ahora se puede informar a las familias de que la evidencia hasta la fecha sugiere que el riesgo de que el recién nacido adquiera infección durante la hospitalización del parto es bajo cuando se toman precauciones para proteger a los recién nacidos de las secreciones respiratorias infecciosas maternas. Este riesgo parece no ser mayor si la madre y el bebé se adentran juntos utilizando medidas de control de la infección en comparación con la separación física del bebé en una habitación separada de la madre. (AAP, 2020)

Otro aporte que se considera valioso mencionar es el resumen elaborado por Sola et al. (2020), debido a que, basándose en varios estudios, han identificado varias premisas que hasta ahora son sustentadas respecto a los RN y el contexto de COVID-19 en el que les ha tocado desarrollarse. Entre otros aspectos, se señala que:

- La transmisión vertical de coronavirus de madre a hijo durante el tercer trimestre del embarazo es poco probable.

- Después del nacimiento un recién nacido es susceptible de contagio horizontal.

- Muy escaso número de RN reportados con 2019-nCoV positivo hasta la actualidad. Asintomáticos o leves. Tal vez (incierto) 1-3 RN fallecidos en el periodo neonatal con COVID 19 confirmado.

- El virus no se ha detectado en el líquido amniótico, placenta, la leche materna $u$ otras muestras maternas.

- La leche materna brinda protección contra muchas enfermedades y es la mejor fuente de nutrición para la mayoría de los bebés.

- No hay evidencia de trasmisión por lactancia materna.

- La mayoría de los pocos neonatos analizados de hijos de madres infectadas han sido negativos, sin detección del virus.

- Un número muy pequeño de bebés dio positivo poco después del nacimiento. Sin embargo, se desconoce si estos bebés contrajeron el virus antes o después del nacimiento.

- 72 RN "sintomáticos" $\rightarrow$ En 67 virus No demostrado. 
- China, que incluye 9 madres: Todos los niños se mantuvieron asintomáticos, sin detección del virus en placenta, líquido amniótico, leche materna ni en el recién nacido.

En 10 neonatos de madre +, se describe prematuridad en 6 casos (5 de ellos con dificultad respiratoria al nacimiento y 2 con trombocitopenia) y 4 casos a término, uno asintomático y 3 con clínica leve y sin complicaciones. Falleció uno de los prematuros, (con sepsis y asfixia) Nada fue atribuible al virus SARS-CoV-2.

- Los síntomas clínicos de 33 recién nacidos con COVID-19 o con riesgo/sospecha de COVID-19 fueron leves y los resultados fueron favorables. De los 3 recién nacidos con COVID-19 sintomático, el neonato más gravemente enfermo puede haber sido sintomático por prematuridad, asfixia y sepsis, en lugar de infección por SARS-CoV-2.

- 6/9 RN en otra publicación tuvo una enfermedad grave y 1 murió. Sin embargo, todos estos recién nacidos tuvieron resultados negativos para el SARS-CoV-2 en muestras faríngeas recolectadas de 1 a 9 días después del nacimiento para pruebas de amplificación de ácido nucleico.

- Datos muy recientes publicados en el JAMA sugieren que la transmisión durante el embarazo puede ser posible, pero se sigue investigando.
- Neonatos de 40 semanas, hijos de madre con neumonía y nacidos por cesárea, pruebas positivas en muestra de exudado faríngeo tomadas a 24-30 horas de vida. Recién nacidos asintomáticos.

- Estos datos y otros respaldan la evidencia actual de la baja prevalencia de COVID-19 en los recién nacidos. Además, actualmente es imposible sacar conclusiones definitivas sobre la causa última de la gravedad de la enfermedad o la muerte debido a COVID-19 en los recién nacidos.

- La transmisión vertical de SARSCoV-2 durante el tercer trimestre es al menos poco común y parece que el virus no pasa a la leche materna. (...) (Sola et al., 2020, págs. 13-14)

No obstante, de las deducciones de Zhi-Jiang et al. (2020), quienes han basado sus estudios en la observación de cuatro bebés menores de 28 días de vida con infección por COVID 19 nacidos de madres infectadas con síntomas leves, es posible rescatar que:

Los síntomas de la infección neonatal son generalmente leves en comparación con los pacientes adultos. No se notificaron complicaciones clínicas graves ni muertes, en comparación con las tasas de mortalidad del $4 \%$ $15 \%$ en adultos (...) Es alentador que los recién nacidos y los bebés parezcan ser menos vulnerables al SARSCoV-2. Por otro lado, los síntomas leves o no en los más pequeños difi- 
cultan la detección y prevención de la transmisión posterior.

[...] Es posible que la transmisión vertical sea una vía adicional para las infecciones neonatales, aunque un estudio previo de 6 mujeres embarazadas no encontró ninguna evidencia directa.

[...] Los resultados del presente estudio apoyan el potencial de transmisión intrauterina. Los 4 recién nacidos fueron entregados por cesárea y 3 estaban bajo protección de nivel III. Se excluyó la posibilidad de transmisión intraparto de madre a hijo por parto vaginal. A excepción de que el Paciente 2 tuviera contacto con un visitante infectado, todos los otros 3 recién nacidos estaban aislados cuando se presentaban los síntomas. No se produjo contacto maternos-hijo ni la lactancia materna en los 3 recién nacidos. El tiempo entre el nacimiento y el diagnóstico fue limitado, oscilando entre 30 h y 5 días. En conjunto, la posibilidad de infección a través de formas distintas de la transmisión intrauterina se considera baja. Sin embargo, hay otras explicaciones para las infecciones neonatos. En primer lugar, no se puede descartar por completo la posibilidad de infección nosocomial. En segundo lugar, los hisopos nasofaríngeos y anales no pueden indicar directamente la infección intrauterina, y no se encontraron partículas virales en el líquido amniótico o la sangre del cordón umbilical de 6 pacientes. En tercer lugar, el número de infecciones neonatales es pequeño, aunque es posible una identifica- ción incompleta. En cuarto lugar, no se encontró que el SARS-CoV, otro coronavirus con secuencia genómico similar, se transmitió verticalmente. Se justifican más investigaciones.

Hay limitaciones en el presente estudio. En primer lugar, aunque se realizó una búsqueda sistemática y exhaustiva de la infección por SARS-CoV-2 en recién nacidos y 28 días de edad, es posible identificar incompletamente los casos. En segundo lugar, el presente estudio identificó en su mayoría pacientes sintomáticos. Sin embargo, existe una infección asintomática para Covid-19. En tercer lugar, no se recogieron muestras de tejido intrauterino para estos 5 recién nacidos. La detección directa de SARS-CoV-2 no es posible en el presente estudio.

En resumen, los recién nacidos son susceptibles a la infección por SARSCoV-2. Los síntomas en los recién nacidos fueron más leves y los resultados fueron menos graves en comparación con los adultos. La transmisión vertical intrauterina es posible, pero todavía faltan pruebas directas.

La Asociación Mexicana de Pediatría (2020) por su parte a reseña que, en cuanto a las manifestaciones clínicas en el RN con COVID-19:

Se ha observado que la mayoría (>90\%) de recién nacidos de madres con COVID-19 son asintomáticos y no presentan complicaciones al nacer, incluidos aquellos en donde se corrobora infección por SARS-CoV-2. Algunas manifestaciones clínicas observadas en los recién nacido con

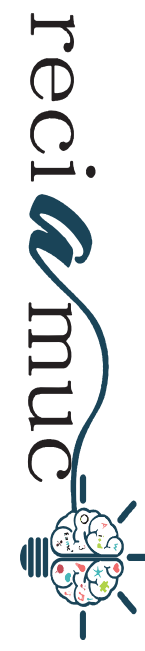


infección de SARS-CoV2 confirmada son:

- Nacimiento pretérmino (4 casos)

- Fiebre (4 casos)

Vómito (3 casos)

- Letargia (2 casos)

- Dificultad respiratoria (2 casos)

Tos (2 casos)

- Sepsis (1 caso), probablemente asociado a prematuridad e infección por E. agglomerates.

En un reporte de 10 recién nacidos de madres con diagnóstico de COVID-10 se observó además dificultad para respirar (6 casos), sangrado gástrico (4 casos), síndrome de dificultad respiratoria neonatal (2 casos), neumotórax (1 caso) y muerte por choque refractario y falla orgánica múltiple (1 caso). Sin embargo, ninguno fue positivo para SARS-CoV-2 y no hubo evidencia de transmisión vertical, por lo que los síntomas parecen estar relacionados al nacimiento pretérmino.

[...] Los hallazgos en estudios de laboratorio suelen ser inespecíficos. En recién nacidos con infección confirmada por COVID-19 se ha reportado al nacimiento leucocitosis o leucopenia con linfopenia, trombocitopenia, transaminasemia, hiperbilirrubinemia. También se ha documentado leve aumento de mioglobina y CPK al nacimiento en un caso pero sin ningún síntoma clínico. Incremento de los reactantes de fase aguda, como procalcitonina, y proteína $\mathrm{C}$ reactiva.
Los hallazgos radiográficos en el recién nacido con COVID-19 también son inespecíficos compatibles con neumonía. En algunos casos se ha realizado tomografía de tórax la cual puede ser normal o mostrar patrón intersticial, vidrio despulido o infiltrados en parches irregulares. (págs. 1-2)

De Xiao, Yan, Wang, \& Zhou (2020) es posible despejar de manera más precisa que, son las condiciones subyacentes en el RN, tales como la prematuridad o la cardiopatía, las que aunado a la confirmación de COVID19 derivarían en una enfermedad respiratoria severa. No obstante, dejaron claro que igualmente pueden afectarse los sistemas respiratorio, gastrointestinal y cardiovascular, pero por lo general, los RN desarrollan la COVID 19 levemente por lo que no requerirán su ingreso a la unidad cuidados intensivos neonatales (UCIN), y su pronóstico tenderá a ser más favorable que desfavorable.

Estos expertos también han destacado la importancia del diagnóstico diferencial en los $\mathrm{RN}$, sobre todo en aquellos en los que se han detectado comorbilidades como inmunodeficiencias, cardiopatía congénita, enfermedades metabólicas hereditarias, neuromusculares, entre otras; ya que "Las manifestaciones neonatales de COVID-19 son indistinguibles de NRDS [síndrome de dificultad respiratoria neonatal], taquipnea transitoria, neumonía, sepsis, etc." (Xiao et al., 2020, pág. 281)

En una reciente publicación de la 
Asociación colombiana de infectología (ACIN) sobre la atención, diagnóstico y manejo de la infección por SARS-COV-2/COVID-19 se hace referencia a los factores de riesgo asociados a las complicaciones por ésta infección, asegurando que estas pueden ser: "inmunosupresión primaria o secundaria, edad menor de 1 año, coinfección viral del tracto respiratorio inferior, comorbilidades como enfermedades cardiacas congénitas, fibrosis quística, displasia broncopulmonar" (pág. 16); varios estados patológicos o condiciones a los que, de hecho, un RN pudiera no estar exento. Sin embargo, en el mismo compendio de recomendaciones se deja igualmente claro que, especialmente en pacientes neonatos, la prematuridad y las malformaciones congénitas deben asumirse como factores de riesgo adicionales. (ACIN, 2020)

La OMS (2020) ha informado que un reciente estudio, que consiste en "investigaciones en curso de ámbito mundial que compilan y sintetizan datos sobre la situación de las embarazadas con COVID 19 en países de todo el mundo" se ha llegado a concluir que las embarazadas o las puérperas con COVID 19 reportan una mayor probabilidad de dar a luz prematuramente $y$, de hecho, la relación de ingresos de $\mathrm{RN}$ procedentes de madres infectadas con dicha enfermedad a la unidad de neonatología fue de 1:4, sin embargo, se reconoce que aún faltan datos sobre las causas de los partos prematuros o indicaciones sobre dichos ingresos.
De este reciente reporte, es posible atreverse a inferir, quizás y hasta cierto punto, la infección por SARS-CoV-2 en las embarazadas pudiera estar influyendo de alguna forma en el desarrollo gestacional, lo que al final está derivando en prematuridad fetal, y que a su vez compone una condición en el RN que a corto plazo lo expone al riesgo de complicaciones por un síndrome respiratorio agudo severo.

\section{Conclusión}

Sobre la base de las fuentes de datos utilizadas en este estudio se puede deducir que, en general, las investigaciones que se relacionan con el análisis de casos de recién nacidos infectados por la COVID 19, tienden a sugerir con sus evidencias que éstos pacientes resultan padecer sólo los síntomas leves de dicha enfermedad, por lo que resultan ser menos vulnerables ante el SARS-CoV-2 y, por ende, terminan reportándose con un mejor pronóstico.

De la misma manera fue posible deducir que los riesgos a los que pudieran estar expuestos los $\mathrm{RN}$ ya infectados con SARS-CoV-2, por el momento, pudieran ser las mismas complicaciones o comorbilidades que generalmente afectan a este grupo poblacional, tales como: las malformaciones congénitas, cardiopatías congénitas, trastornos respiratorios, trastornos metabólicos, trauma obstétrico, la prematuridad, bajo peso al nacer, ictericia neonatal, sepsis neonatal, policitemia neonatal, hipoglucemia neonatal, apneas, inflamación 
intestinal grave, hemorragia cerebral, entre otras. Éstas, en definitiva, incrementan las posibilidades de secuelas (permanentes o no), e incluso, la muerte; sin embargo, todavía no existe evidencia concluyente que sustente una clara relación entre tales morbilidades y el riesgo que representa para un RN con la COVID 19.

\section{Bibliografía}

AAP. (10 de septiembre de 2020). Management of Infants Born to Mothers with Suspected or Confirmed COVID-19. Recuperado el 11 de septiembre de 2020, de https://services.aap.org/en/pages/2019-novel-coronavirus-covid-19-infections/clinical-guidance/faqs-management-of-infants-born-to-covid-19-mothers/

ACIN. (26 de marzo de 2020). Infectio, 24(3 (S1)), 45 pp. Recuperado el 01 de 09 de 2020, de http://revistainfectio.org/index. php/infectio/article/download/853/949

ASCON. (21 de junio de 2020). Recomendaciones para unidades neonatales frente a casos positivos por virus SARS-CoV-2/COVID-19. Recuperado el 05 de septiembre de 2020, de https://ascon.org.co/wp-content/uploads/2020/06/21.06.2020-Recomendaciones-UCIN-COVID-19-1.pdf

Asociación Mexicana de Pediatría. (25 de abril de 2020). COVID-19 en el Recien nacido. Recuperado el 10 de septiembre de 2020, de http://www.funsalud.org. mx/wp-content/uploads/2020/05/COVI-EN-RECIEN-NACIDO.pdf

Berberian, G. (2020). La COVID-19 en bebés recién nacidos: Informarse y prevenir. Recuperado el 02 de septiembre de 2020, de https://portalgarrahan.org/como-puedo-proteger-a-ninos-y-ninas-recien-nacidos-y-pequenos-de-la-covid-19-2/

Centros para el Control y Prevención de Enfermedades de los Estados Unidos de
América. (26 de agosto de 2020). Investigación del impacto del COVID-19 durante el embarazo. Recuperado el 03 de septiembre de 2020, de https://espanol.cdc. gov/coronavirus/2019-ncov/cases-updates/special-populations/pregnancy-data-on-covid-19/what-cdc-is-doing.html

Ministerio de Salud de Argentina. (19 de mayo de 2020). COVID-19 Estrategias para la atención en la UCIN del recién nacido hijo de madre sospechosa o positiva. Recuperado el 02 de septiembre de 2020, de https://www.intramed.net/contenidover. asp? contenidoid=96143\&pagina $=1$

Ministerio de Salud Pública y Bienestar Social del Paraguay. (16 de marzo de 2020). Coronavirus COVID-19. Manejo Clínico en Pediatría. Recuperado el 02 de septiembre de 2020, de https://www. mspbs.gov. py/dependencias/portal/adjunto/850c83-COVID19ManejoenPediatra25.03.2020.pdf

OMS. (27 de marzo de 2020). Recomendaciones para el cuidado integral de mujeres embarazadas y recién nacidos. Recuperado el 02 de septiembre de 2020, de https://www.paho.org/clap/images/PDF/ COVID19embarazoyreciennacido/COVID-19_embarazadas_y_recin_nacidos_ CLAP_Versin_27-03-2020.pdf?ua=1

Sola, A., Maksimovic, L., Montes, M., Rodríguez, S., Cardetti, M., Golombek, S., \& Morgues, M. (17 de abril de 2020). Sociedad Iberoamericana de Neonatología y COVID-19 perinatal: Información y recomendaciones de SIBEN. (EDISIBEN, Ed.) Recuperado el 02 de septiembre de 2020, de http://www.siben.net/images/files/sibensarscov2covid19asolav2.pdf

Xiao, T.-T., Yan, K., Wang, L.-S., \& Zhou, W.-H. (2020). What can we learn from neonates with COVID-19? World Journal of Pediatrics, 16, 280-283. doi:10.1007/ s12519-020-00376-y

Zhi-Jiang Zhang, X.-J. Y. (2020). Nueva in- 
fección por coronavirus en bebés recién nacidos menores de 28 días en China. European Respiratory Journal - ERS, 56(3). doi:10.1183/13993003.00697-2020

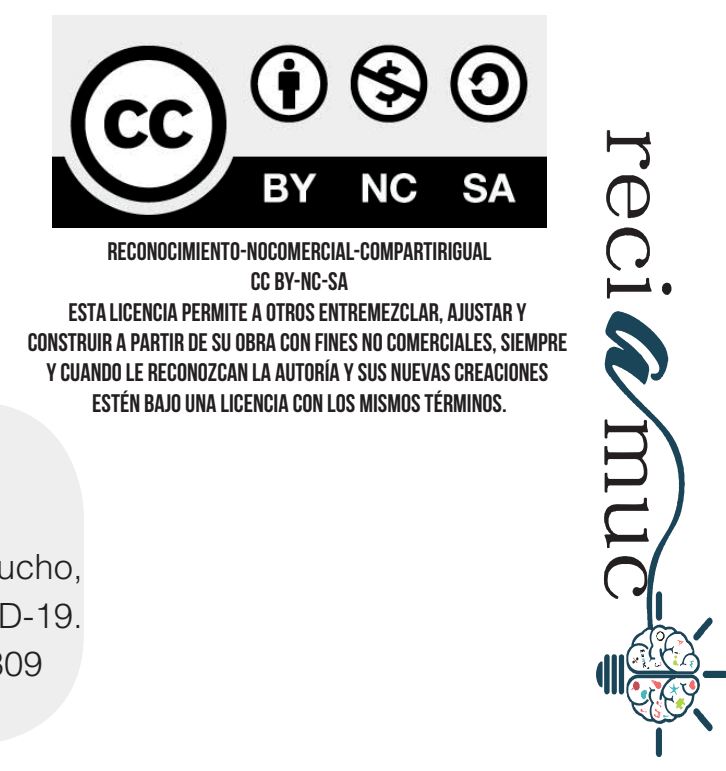

